\title{
Alzheimer's Disease: Neurotransmitters Involved and the Possible New Strategies
}

\author{
Sushma Ror Maratha ${ }^{1}$, Neha Falls ${ }^{2}$, Neelam Vashist ${ }^{1}$, Sonia Yadav ${ }^{1}$, Vinod Gahlot ${ }^{1 *}$ \\ ${ }^{1}$ S.G.T. College of Pharmacy, Shri Guru Gobind Singh Tricentenary University, Gurugram \\ ${ }^{2}$ Sam Higginbottom Institute of Agriculture, Technology and Sciences, Naini, Allahabad, Uttar Pradesh. 211007
}

Address for Correspondence: Vinod Gahlot, gahlotvinod04@gmail.com

\section{Received:}

16.03.2018

Accepted:

08.06 .2018

Keywords

Alzheimer'

disease; tau

protein;

Cholinergic

system; Memory;

Dementia.

\begin{abstract}
Alzheimer's Disease (AD) is the progressive neurodegenerative disorder associated with many pathophysiological conditions. The aim of present review is to understand the learning and cognitive processes and study the various parameters related to Alzheimer's Disease. The pathophysiological mechanism of the $\mathrm{AD}$ has been studied and neurotransmitters used in learning process and cognitive function have been described. The main pathophysiological symptom behind $A D$ is $\beta$-Amyloid plaque and neurofibrillary entangles. The other reasons of $\mathrm{AD}$ include synaptic failure, decrease in calcium regulation, inflammatory mediators, problem in insulin signaling, depletion of neurotransmitters, oxidative stress and mitochondrial dysfunction. Cholinergic system is the major system involved in the learning and cognitive behaviour. The roles of various other neurotransmitters like angiotensin, GABA, dopamine, adrenaline, serotonin, histamine, nitric oxide and nerve growth factors have also been described. The neurotransmitters like acetylcholine, adrenaline and dopamine have been found to improve cognitive behaviour while NMDA, GABA, serotonin, histamine and angiotensin have diminishing effect on memory. (C) 2019 iGlobal Research and Publishing Foundation. All rights reserved.
\end{abstract}

Cite this article as: Maratha, S.K.; Falls, N.; Vashist, N.; Yadav, S.; Gahlot, V. Alzheimer's disease: neurotransmitters involved and the possible new strategies. Indo Global J. Pharm. Sci., 2019; 9(1): 5- 12. DOI: http://doi.org/10.35652/IGJPS.2019.9102.

\section{INTRODUCTION}

Alzheimer disease was first identified by Dr. Alois Alzheimer in 1907 while examining a 51 year old year women who was suffering from relatively rapidly deteriorating memory along with psychiatric disturbances [1]. Numerous of increasing and fatal neurological changes, including senile dementia, the early age at onset, and pathophysiological finding, the neurofibrillary tangle, were known at that time. Over time, AD was divided into two clinical states depending upon the age of onset of disease. Alzheimer disease, restrained for a type of "presenile" have an effect on individuals younger than 65 year of age, was mentioned to as senile dementia [2].
Alzheimer's disease (AD) is a progressive, neurodegenerative, chronic brain disorder designated by cognitive problems, cholinergic imbalance, tau and $\beta$-amyloid pathology and vascular injury. Loss of cortically predictions cholinergic neurons, specifically in brain areas related with memory and learning. The key features include $\beta$-amyloid plaques and tau pathology, vascular diseases, neuronal cell morbidity, and inflammatory responses. It is suggested that the factors affecting blood vessels which includes increased levels of cholesterol in blood, type 2 diabetes and hyperhomocysteinemia causes either damage to the cerebrovascular system comprising of silent stroke or causes dysregulation of $\beta$-amyloid clearance at the blood-brain barrier 


\section{Indo Global Journal of Pharmaceutical Sciences, 2019; 9(1): 5-12}

resulting in increased brain $\beta$-amyloid [3]. The discrimination of vascular dementia from $\mathrm{AD}$ is dependent on evidence of a cerebrovascular disorder. There are unusual less cases of pure vascular dementia without neurodegenerative changes. The autopsy of clinically diagnosed vascular dementia emphasized on the presence of pathological signs of AD. Mild cognitive impairment has been defined as the earliest forms of dementia that may partly convert into AD [4].

\section{NEUROMODULATORS USED IN LEARNING PROCESS AND MEMORY}

Various Neurotransmitters, Neuromodulators and their associated receptor systems used in learning and memory processes are given below:

\section{Role of Cholinergic System}

The decrease in cognitive ability is mostly related to a suppression of cholinergic neurotransmission. Nicotine and nicotinic agonists have been found to upgrade cognition in animals [5]. Increased contact with nicotine results in positive changes on central cholinergic neurotransmitters and memory function [6]. Acetylcholinesterase (AChE) is an enzyme that blocks the effects of acetylcholine at the neurohumoral junctions of cholinergic nerve endings [2]. Anticholinesterase agents that are capable of crossing the blood-brain barrier have shown efficacy in the treatment of AD. Biochemical investigation of the samples obtatined from the brains of $\mathrm{AD}$ suffering patients shows reduction in nicotinic acetylcholine receptors (nAChRs), a potentiation in butyrylcholinesterase, reduction in Ach and inactivating enzymes [7]. Butyrylcholinesterase and AChE help abolish Ach demonstrate by hydrolyzing the transmitter, thereby inactivating it. The most unguarded neurons in $\mathrm{AD}$ appears to be those showing increased levels of nAChRs, particularly those containing the $\alpha 7$ subunit [8], and the numbers of nAChRs in addition to few of their linked proteins change in $\mathrm{AD}$ [9]. Not only have $\alpha 7 \mathrm{nAChRs}$ been found be localized with plaques but $\alpha 7$ and $\alpha 4$ subunits are also positively corrected with neurons that accumulate amyloid $\beta$ (A $\beta)$ [10]. It is sure that $\mathrm{AD}$ involves damage to neurons of cholinergic nervous system in brain in addition to an overall decrease in nAChRs, and it appears that various subunits are differentially up or down-regulated in $\mathrm{AD}$ in different brain parts and various cell types.

\section{Role of Dopaminergic System}

Dopamine, being the major catecholamine neurotransmitter in the mammalian brain, controls various functions, involving food intake, locomotor activity, emotion, cognition, and endocrine management. Cerebral levels of dopamine and its active metabolite homovanillic acid have been documented to be reduced in cortex and amygdala regions of patients diagnosed with AD. Dopamine (DA) receptor agonist, pergolide has been found to improve memory in human beings [11]. $\mathrm{D}_{2}$ dopamine receptor antagonist, (-)-sulpiride, showed antagonizing effect on the memory enhancing effect of caffeine [12].

\section{Role of Serotonergic System}

Role of various 5-HT receptors in the physiology of memory processes and their adjustment by the serotonin depletor $\mathrm{p}$ chlorophenylalanine (pCPA) has been shown in rats using shuttle box [13]. 5- $\mathrm{HT}_{2}$ antagonist, mianserin improved cognitive function in chronic schizophrenic patients [14]. 5$\mathrm{HT}_{3}$ receptor antagonist, ondansetron improved learning and cognitive behaviour in animal models [15]. 5-HT reduces long term potentiation (LTP) in hippocampal portion by preventing the activation of NMDA receptors and the increase of AMPAmediated currents that leads to LTP induction [16]. The presynaptic $5-\mathrm{HT}_{1 \mathrm{~A}}$ receptors decrease glutamate secretion [17]. $5-\mathrm{HT}_{1 \mathrm{~B}}$ receptors are located on the axons terminals of Cauda Aquna 1 pyramidal neurons. The memory impairment was seen after a treatment with $5-\mathrm{HT}_{1 \mathrm{~B}}$ agonists is may be the result of reduction in excitatory neurotransmission in circuits which are part of the hippocampus activity [18].

\section{Role of GABA-ergic System}

Muscimol, a $\mathrm{GABA}_{\mathrm{A}}$ receptor agonist was found to impair retrieval in rodents, when administered immediately after acquisition trial [19]. On the other hand, bicuculline is a $\mathrm{GABA}_{\mathrm{A}}$-antagonist when injected 30 minutes prior to training, enhanced memory in chicks [20] and in rats [21]. Baclofen, a $\mathrm{GABA}_{\mathrm{B}}$ receptor agonist, impaired spatial learning in rats through activation of presynaptic $\mathrm{GABA}_{\mathrm{B}}$ receptors in a dose dependent manner [22]. Activation of $\mathrm{GABA}_{\mathrm{A}}$ and $\mathrm{GABA}_{\mathrm{B}}$ receptors may be involved in the processes leading to impairment of memory [23]. $\mathrm{GABA}_{\mathrm{A}}$ receptors negotiate fast-acting inhibitory actions in the brain and activation of $\mathrm{GABA}_{\mathrm{A}}$ receptor cause hyperpolarization and decreased activity of neurons. Compounds that enhance the action of GABA can impair memory processing, while the compounds that reduce the action of GABA can enhance memory processing, especially the possession process [24].

\section{Role of Histamine}

Histamine plays a crucial role as a neurotransmitter in the central nervous system and actively participates in various physiological functions across specific receptors including the $\mathrm{H} 1, \mathrm{H} 2, \mathrm{H} 3$ and $\mathrm{H} 4$ histamine receptors [5]. The $\mathrm{H} 1, \mathrm{H} 2$, and $\mathrm{H} 3$ subtypes are expressed in the CNS, and H4 subtype is only 


\section{Indo Global Journal of Pharmaceutical Sciences, 2019; 9(1): 5-12}

found in periphery, specifically in bone marrow and leukocytes [25]. It has been accepted that histamine with other transmitter systems involve in higher brain tasks such as memory and learning [26]. The earlier reports also showed that co-administration of sulpiride with histamine during repeated pre-treatment of histamine reversed the amnesia induced by post-training histamine [23]. Histamine and histidine improved short term-memory and reversed the spatial memory loss induced by MK-801, probably through postsynaptic $\mathrm{H}_{1}$-receptors [27]. Thioperamide, the first specific $\mathrm{H}_{3}$-receptor antagonist improved memory consolidation and reversed the cognitive dysfunction induced by scopolamine or dizocilpine [28]. An injection of clobenpropit (5, 10 ug per site, depending on dose) markedly improved the reference memory with emphasis on day to day memory effect initiated by MK-801, probably through increased release of endogenous histamine [27]

\section{Role of NMDA (N-methyl-D-aspartate)}

Activation of NMDA receptor was reported to affect learning and cognitive behaviour [29] Memantine, a non-competitive NMDA receptor antagonist, marketed for treatment of $\mathrm{AD}$ [30]. Memantine has neuroprotective properties and can block $\beta$-amyloid induced neurodegeneration [31]. Glutamate activates a variety of postsynaptic receptors, including the $\mathrm{N}$ methyl-D-aspartate (NMDA) receptor, which has been specifically involved in memory procedure, dementia, and the pathophysiological progression of AD. Glutamate receptors when stimulated, produces Reactive Oxygen Species (ROS) and involvement of programmed cell-death series [32].

\section{Role of Angiotensin Converting Enzyme (ACE)}

The brain RAS plays a crucial role in the management of neurogenic hypertension [33], cerebrovascular fluid homeostasis [34] and sodium intake [35]. Latest studies show clinical and experimental proof has suggested that brain RAS has participated in strokes [36], in addition to other neurological diseases, such as AD [37], and Parkinson's disease [38], Angiotensin II regulates long term memory appearance but does not affect memory storage [39]. ACE inhibitors like captopril and enalapril have shown to improve cognition in different animal models of memory and learning [40]

\section{Role of Nerve Growth Factor}

Nerve growth factor (NGF) is the most important parameter to defend cholinergic neurons from neurodegeneration [41]. Nerve Growth Factor (NGF), Brain-Derived Nerve Factor (BDNF), Glial-Derived Nerve Factor (GDNF) - intricated in the result of neurodegenerative diseases. Different neurons will depend upon various growth factors to protect themselves from continuous damages, for example NGF protects cholinergic system neurons most probable injuries[42], where as for dopaminergic neuron, the effect is more efficiently maintained by BDNF [43].

\section{Role of Nitric Oxide}

Release of NO free radical in brain leads to neurodegeneration and hence may provoke memory impairment [44]. L-arginine, which is a nitric oxide donor, improved memory of rats [45]. Only three isoforms of nitric oxide synthase (NOS) have been discovered till date and they are named depending to the cell types from which they were first separated. They are designated as neuronal NOS, inducible NOS and endothelial NOS nNOS iNOS eNOS respectively [46,]. These NOSs have varied functions [47], the expression of nNOS and eNOS are composed and maintained by calmodulin and calcium. Endothelial NO (eNO) and Neuronal nitric oxide (nNO) are produced at little rates by eNOS and nNOS, respectively [48]. Excessive production of iNO is detrimental by inducing the inflammatory process and possibly AD. Molsidomine, a nitric oxide donor reversed scopolamine-induced and aging-induced amnesia in rats [49].

\section{Role of Oxygen Free-Radicals}

Drugs or vitamins that possess antioxidant properties may decrease neuronal destruction and finally slow the development of $\mathrm{AD}$. Antioxidant-rich diets improved cerebellar functions and motor learning in older rats [50]. Vitamin $\mathrm{E}$ administration prior to and followed by ozone exposure prevented memory deterioration [51]. Reduced levels of oxygen or glucose, increased oxidative stress [52], contact to toxins or other pathogenic agents, and transmission of a disease generating mutation can initiate the neurodegenerative process due to release of oxygen free radicals. Mediators of the neuroendocrine stress response produced due to neuroendocrine and behavioral changes affect neuronal homeostasis. This imbalance may participate in the progression of hypertension, atherosclerosis, insulin resistance, and other peripheral disturbances that may indirectly initiate neuropathological changes that add to the progression of $\mathrm{AD}$ [53]. Reactive oxygen species plays a significant role in mediating molecular injury in neuroinflammation which relates traumatic brain injury to increased risk of neurodegeneration. Additionally, these reactive species may supplementary produce a suitable therapeutic target to decrease the threat of post-injury neurodegeneration and offer long term quality of life improvements for those affected from distressing brain injury [54]. 


\section{Indo Global Journal of Pharmaceutical Sciences, 2019; 9(1): 5-12} NEW STRATEGY IN TREATMENT OF

\section{AD}

Studies point toward that phytic acid influences multiple processes, including antioxidant functions anti-apoptotic effects. DNA repair and mRNA export from the nucleus. Some of its properties may have a favourable effect on brain aging and $\mathrm{AD}$ pathologic changes, which can be classified as (1) mimicking caloric restriction, (2) promoting autophagy and (3) regulating clathrin-coated endocytosis of Amyloid originator protein and their cleavage products. Reducing amyloid plaque burden via ex vivo gene delivery of A $\beta$-degrading protease Iron chelators is a promosing new Alzheimer therapy. The role of $\mathrm{A} \beta$ mortification in the removal of the $A \beta$ peptide is becoming more broadly understood and appreciated. Proteases neprilysin, insulin-degrading enzymes 1 and 2, plasmin, and cathepsin $B$ are capable of regulating $A \beta$ levels in vivo [55]. Supporting a therapeutic over expression and direct viral vector injection of these enzymes has been shown to lower A $\beta$ levels significantly [56]. Oxidative damage regulated by metals is probably a notable contributor since metals such as iron, aluminium; zinc and copper are deregulated in $\mathrm{AD}$ brain tissue and form a pro-oxidative atmosphere. Desferrioxamine may be used to reduce the harmful effects produced by increased iron levels in the body, but desferrioxamine also has its own limitations such as diminished tissue targeting, hence may be used with precaution[57]. The role of Aluminum has also gathered attention but its role has never been properly elaborated. Aluminum has been found in high concentrations in both senile plaques and intraneuronal neurofibillary entangle in the brains of individuals with $\mathrm{AD}$, which emphasizes that this metal may be occupied in the pathogenesis of $\mathrm{AD}$ [3]. The role of other metals involved in the progression of $\mathrm{AD}$ have been strongly emphasized which includes copper [58, 59] and zinc [3]. In mouse models of AD, the decrease in the severity of beta-amyloid plaque pathologenesis and reverse cognitive deficits has been demonstrated. Singlechain fragment antibodies can be used to neutralize or alter $\mathrm{A} \beta$-related neurotoxicity and inhibit its aggregation in vitro instead of using of passive immunization with full $\mathrm{IgG}$ antibodies.

Cholinesterase inhibitors (ChEIs) are also playing a vital role in the management of Alzheimer's disease [60]. Apart from this ChEI are at present used as the first-line drugs for patients suffering with mild-to-moderate Alzheimer's related dementia (AD) [61]. Differences in the pharmacodynamic and pharmacokinetic profiles between different Cholinesterase inhibitors may provide a clinical advantage after switching to another ChEI[62].
Galantamine has been known to improve common $\mathrm{AD}$ symptoms or slowing of the rate of cognitive decline in $\mathrm{AD}$ [63]. Soluble oligomers (soA $\beta$ ), a subtype of $\beta$-amyloid (A $\beta$ ) peptide, may be responsible for memory loss in $\mathrm{AD}$. Removal of these soluble or insoluble structures may be beneficial in stabilizing brain functions and retarding the process of memory decline in $\mathrm{AD}$. In the new therapy for the treatment of $\mathrm{AD}$ includes naturally occurring polyclonal antibodies of IV Immunoglobins (IVIg) [64]. Multitarget Tacrine Hybrids are proficient of identifying reactive oxygen species (ROS) and derivatives which help in reducing the formation of $\mathrm{A} \beta$-plaques either directly by confronting the A $\beta 1-42$ self aggregation process or indirectly by inhibiting the BACE-1 enzyme or AChEinduced A $\beta 1-40$ aggregation. Particular interest is also addressed to THA hybrids with suppressed hepatotoxicity[65, 66, 67]. A new drug Huperzine can also improving the cholinergic activity anti- $\beta$-amyloid aggregation, scavenging of radical oxygen species [68]. Minocycline has the power of crossing the blood brain barrier and has neuroprotective capabilities that work by restraining inflammation and oxidative stress [69]. New A $\beta$ antibodies (solanezumab, gantenerumab, crenezumab) and inhibitors of $\beta$-secretase --MK-8931, E2609 and 5-HT6 antagonist (idalopirdine, encenicline) block the modified glycation end product receptors by azeliragon or modulation of the acetylcholine response of $\alpha-7$ nicotinic acetylcholine receptors [70]. The side effects associated with high doses such as nausea, abdominal pain, anorexia, $\&$ vomiting. Low compliance because of high incidence of dysphagia and memory dysfunction and variation of blood concentration of drugs are present with oral drugs. Other effects including renal failure, hepatotoxicity, asthenia, or malaise may lead to discontinuation of treatment in many cases. The new therapeutic appraoach for the treatment could only be transdermal delivery system because of their ability to bypass the first-pass metabolism as the drugs are absorbed directly into the blood through the skin to enable use at low doses and circadian cholinergic rhythms would be unaffected. Furthermore, transdermal drug delivery system provides a controlled availability of drug and gives regulated therapeutic levels of the drug in systemic circulation. This will also reduce the side effects by discarding the large fluctuations of plasma concentration of the drug, and is particularly useful for patients with discomfort in swallowing. Transdermal patches would increase the benefits in prolonged use, will enhance patient compliance and will be preferred by caretaker of the patient during long-term treatment of disease [71]. Formation of protein amyloid- $\beta(A \beta)$ plaques is frequently seen in $A D$ patients. $A \beta$ hinders synaptic neurotransmission which may 


\section{Indo Global Journal of Pharmaceutical Sciences, 2019; 9(1): 5-12}

be underlying mechanism of dementia [72]. Escitalopram, a neurotransmitter based, serotonin reuptake inhibitor, improves neuropsychiatric symptoms (agitation) and Aducanumab, an anti-amyloid drug acting through monoclonal antibodies may remove amyloid plauque formation are currently under phase III of $\mathrm{AD}$ drug development (as of January 30, 2018). [73]

Table 1. Category wise list of drugs with their mechanism of action showing promising effects in the prevention $\&$ progression of $\mathrm{AD}$.

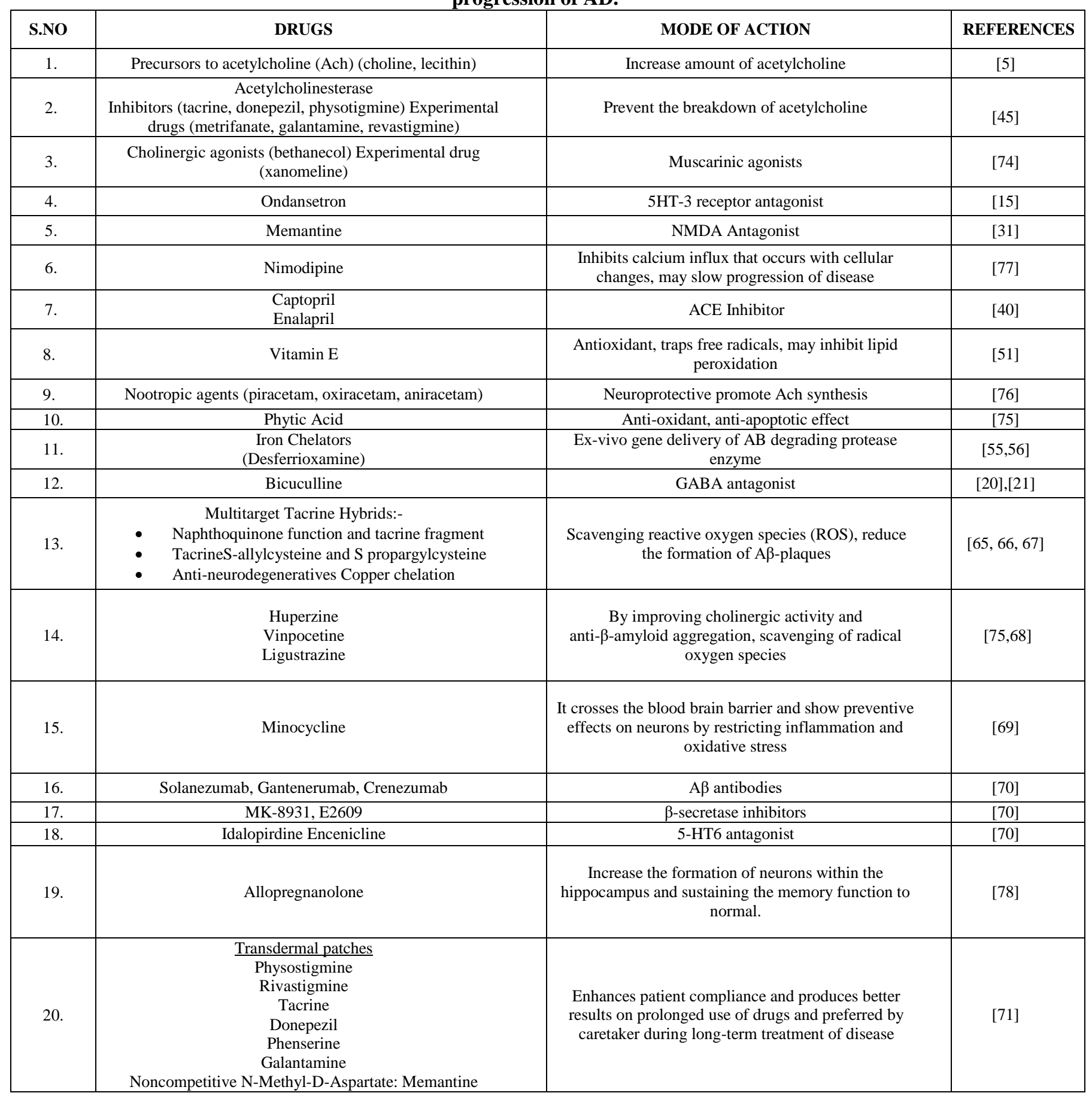




\section{Indo Global Journal of Pharmaceutical Sciences, 2019; 9(1): 5-12}

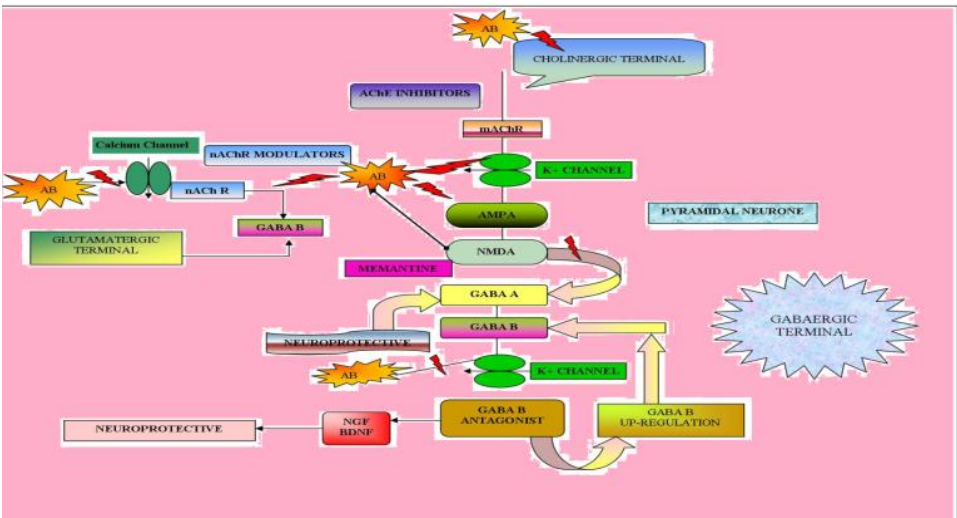

Fig 1: Schematic Representation of Synaptic Dysfunction in Alzheimer's Disease.

Schematic representation showing the role of $A \beta$ in the path physiology of $\mathrm{AD}$ and different sites of drug action. $\mathrm{A} \beta$ induced neurodegeneration resulting in decrease in synaptic terminals neurotransmission. Chronic exposition to $A \beta$ induces neuronal death. Memory loss is related with $A \beta$ synaptic dysfunction on inhibitory \& excitatory receptors \& neurotransmission. Recent studies indicate involvement of both glutaminergic (NMDA-type glutamate receptor antagonists i.e. memantine) \& cholinergic (I.e. ACE Inhibitors, cholinesterase inhibitors) transmission. Involvement of GABAergic neurotransmission is also studied in the worsening of $\mathrm{AD}$ GABA-A receptor agonists \& selective inverse agonists have neurotropic effects. GABA-B receptors are actively blocked by $\mathrm{A} \beta$, however GABA-B antagonists have positive effect in preventing worsening of AD. However the imbalance between excitatory \& inhibitory neurotransmitters \& their neurotransmission may be responsible for early $\mathrm{AD}$ cognitive dysfunction.

\section{CONCLUSION}

Alzheimer's Disease is a neurodegenerative disorder primarily affecting cognitive ability. The main pathophysiological features include $\beta$ - Amyloid plaques, neurofibrillary entangles and tau hypothesis. Acetylcholine is one of the important neurotransmitter involved in the pathogenesis of AD. Various other neurotransmitters like dopamine, 5-HT, histamine, GABA, NMDA etc that have been reviewed. Reduced levels of dopamine \& its metabolite homovanillic acid in brain are linked with progression of AD. 5-HT associated prevention of activation of NMDA \& increase of AMPA mediated currents resulting in LTP induction is responsible for progression of $\mathrm{AD}$. Histamine through its receptors namely H1 to H4 is widely accepted for its involvement in memory \& learning. NOS isoforms particularly iNO induces inflammatory process in brain leading to $\mathrm{AD}$. The possible treatment for $\mathrm{AD}$ includes dopamine agonists, 5-HT antagonists, histamine agonists \& NO donors apart from other class of drugs. Pergolide \& other DA agonists show promising effects in memory enhancement. 5-HT2 \& 5HT3 antagonists mianserin \& ondensetron respectively improved learning \& cognitive behavior in animal models. Clobenpropit help in improving memory loss initiated by MK-801 by the release of endogenous histamine. Molsidomine, a NO donor reverses scopolamine induced amnesia in rats. Anti- $\mathrm{A} \beta$ antibodies are being studied and developed widely as the possible treatment of Alzheimer's Disease. Phytic acid, A $\beta$-degrading protease, nanoparticles and iron chelators may also prove to have some beneficial effects. Apart from above the various neurotransmitters and their receptors may also be treated as molecular targets for development of new and potential anti-Alzheimer's drugs.

\section{ABBREVIATIONS}

ROS- Reactive oxygen species, NMDA-(N-methyl-Daspartate, NO-Nitric Oxide, A $\beta$ - Amyloid $\beta$, Ach Acetylcholine, LTP- Long Term Potentiation, AMPA- $\alpha$ Amino-3-Hydroxy-5-Methyl-4-Isoxazolepropionic Acid Receptor, NGF-Nerve Growth Factor, BDNF-BrainDerived Nerve Factor, GDNF-Glial-Derived Nerve Factor

\section{REFERENCES}

1. Alzheimer A. Uber eine eigenartige Erkrankung der Hirnrinde Allgemeine Zeits Psychiat PsychischYGerichtlich. Med., 1907; 64:146-8.

2. Weisinger R, Blair-West J, Burns P, Denton D, Tarjan E. Role of brain angiotensin in thirst and sodium appetite of rats. Peptides.,1997; 18:977-84.

3. Christen Y. Oxidative stress and Alzheimer disease. Am. J. Clin Nutr., 2000; 7:621S-9S.

4. Sayre L.M, Perry G, Smith M.A. Redox metals and neurodegenerative disease. Curr. Opin. Chem. Biol., 1999; 3 :220-25

5. Brown R.W, Gonzalez C.L, Kolb B. Nicotine improves Morris water task performance in rats given medial frontal cortex lesions. Pharmacol. Biochem. Behav., $2000 ; 69: 473-78$

6. Hernandez C.M, Jr Terry A.V. Repeated nicotine exposure in rat Effects on memory function, cholinergic markers and nerve growth factor. Neurosci., 2005; 130:997-1012.

7. Francis P.T, Palmer A.M, Snape M, Wilcock G.K. The cholinergic hypothesis of Alzheimer's disease: a review of progress. J. Neurol. Neurosurg. Psychiatry., 1999; 66:137-47.

8. D'Andrea M.R, Nagele R.G, Wang H.Y, Peterson P.A, Lee D.H Evidence that neurones accumulating amyloid can undergo lysis to form amyloid plaques in Alzheimer's Disease. Histopathology., 2001; 38:120 -34

9. Sabe L, Jason L, Juejati M, Leiguarda R, Starkstein S.E. Dissociation between declarative and procedural learning in dementia and depression, J Clin Exp Neuropsychol., 1995; 17:841-8.

10. Wilson I.A, Gallagher M, H Eichenbaum, H. Tanila. Neurocognitive aging: prior memories hinder new hippocampal encoding. Trends Neurosci., 2006; 29: 662-670.

11. Kimberg D.Y, D'Esposito M. Cognitive effects of the dopamine receptor agonist pergolide, Neuropsychologia., 2003; 41(8): 1020-7.

12. Cestari V, Castellano C. Caffeine and cocaine interaction on memory consolidation in mice. Arch International Pharmacodyn Therap., 1996; 331(1):94-104.

13. Phillips M. Functions of angiotensin in the central nervous system, Annu Rev Physiol., 1987; 49:413-35.

14. Poucet B, Benhamou S. The neurophysiology of spatial cognition in the rat. Crit. Rev. Neurobiol., 1997; 11:101-20.

15. LaFerla F.M. Calcium dyshomeostasis and intracellular signalling in Alzheimer's Disease. Nat Rev Neurosci., 2002; 3(11):862-72. 


\section{Indo Global Journal of Pharmaceutical Sciences, 2019; 9(1): 5-12}

16. Strong R, Huang J.S, Huang S.S, Chung H.D, Hale C, Burke W.J. Degeneration of the cholinergic innervation of the locus ceruleus in Alzheimer's Disease, Brain Res., 1991; 542:23-28.

17. Schneider E, Rolli-Derkinderen M, Arock M, Dy M. Trends in histamine research: New functions during immune responses and hematopoiesis. Trends Immunol., 2002; 23:255-63.

18. Moncada S, Higgs A. The L-arginine-nitric oxide pathway. N Engl J Med., 1993; 329:2002-12.

19. Castellano C, McGaugh J.L. Oxotremorine attenuates retrograde amnesia induced by post-training administration of the GABAergic agonists' muscimol and baclofen. Behav Neurological Biology., 1991; 56:25-31.

20. Clements M.P, Bourne R.C. Passive avoidance learning in the day-old chick is modulated by GABAergic agents. Pharmacol Biochem Behav., 1996; 53(3) 629-634.

21. Lukoyanov N.V, Pereira P.A, Paula-Barbosa M.M. Cadete-Lette A. Nerve growth factor improves spatial learning and restores hippocampal cholinergic fibers in rats withdrawn from chronic treatment with ethanol. Exp Brain Res., 2003; 148(1):88-94.

22. Mishima K, Tsukikawa H, Miura I, Inada K, Abe K, Matsumoto Y, et al. Ameliorative effect of NC-1900, a new AVP (4-9) analog, through vasopressin $\mathrm{V}_{1 \mathrm{~A}}$ receptor on scopolamine-induced impairments of spatial memory in the eight- arm radial maze, Neuropharmacol., 2003; 44(4) :541-52.

23. Zarrindast M.R, Rezayof A. Morphine state dependent learning: sensitization and interactions with dopamine receptors. Eur J Pharmacol., 2004; 497:197- 204.

24. Chapouthier G, Venault P. GABA-A receptor complex and memory processes. Curr Top Med Chem., 2002; 2:841-51.

25. Selkoe D.J. Alzheimer's Disease is a synaptic failure. Science., 2002; 298:789-791.

26. Haas H.L, Sergeeva O.A, Selbach O. Histamine in the nervous system. Physiol Rev., 2008; 88:1183 - 1241.

27. Hong M, Lee V.M.Y. Insulin and insulin-like growth factor-1 regulate tau phosphorylation in cultured human neurons. J Biol Chem., 1997; 272(31):19547-53.

28. Bernaerts P, Lamberty $\mathrm{Y}$, Tirelli E. Histamine $\mathrm{H}_{3}$ antagonist thioperamide dose-dependently enhances memory consolidation and reverses amnesia induced by dizocilpine or scopolamine in a one-trial inhibitory avoidance task in mice. Behav Brain Res., 2004 ;154(1) :211-19.

29. Lia Frenkel, Luis Daniel Suárez, Héctor Maldonado, Alejandro Delorenzi. Angiotensin modulates long-term memory expression but not long-term memory storage in the crab Chasmagnathus. Neurobiology of Learning and Memory., 2010; 94: 509-20.

30. Staubli U, Otaky N. Serotonin controls the magnitude of LTP induced by theta bursts via an action on NMDA-receptor-mediated responses, Brain Res., 1994 ;643 (1-2) :10-16.

31. Rogers J, Webster S, Lue L.F. Inflammation and Alzheimer's Disease pathogenesis, Neurobiol Aging., 1996; 5:681-6.

32. A. Bakker, C.B. Kirwan, N.I. Miller, C.E.L Stark. Pattern separation in the human hippocampal CA3and dentate gyrus. Science., 2008; 319:1640-42.

33. Gyurko R, Wielbo D, Phillips M. Antisense inhibition of AT1 receptor mRNA and angiotensinogen mRNA in the brain of spontaneously hypertensive rats reduces hypertension of neurogenic origin. Regul Pept., 1993; 49: 167-74.

34. Petkov V.D, Belchev S, Konstantinova E, Kehayov R. Participation of different 5-HT receptors in the memory process in rats and its modulation by the serotonin depletor p-chlorophenylalanine. Acta Neurobiol Expt (Warsz)., 1995;55(4) :243-252.

35. Wevers A, Monteggia L, Nowacki S, Bloch W, Schutz U, Lindstrom $\mathrm{J}$, et al. Expression of nicotinic acetyl-choline receptor subunits in the cerebral cortex in Alzheimer's Disease: histotopo-graphical correlation with amyloid plaques and hyperphosphorylated-tau protei. Eur J Neurosci., 1999;11:2551-65.

36. Malinski T. Nitric oxide and nitroxidative stress in Alzheimer's Disease. J Alzheimers Dis., 2007; 11:207-18.

37. Kehoe P, Miners S, Love S. Angiotensins in Alzheimer's disease friend or foe? Trends Neurosci., 2009; 32:619-28.

38. Joglar B, Rodriguez-Pallares J, Rodriguez-Perez A, ReyP, Guerra M, J. Labandeira-Garcia. The inflammatory response in the MPTP model of Parkinson's disease is mediated by brain angiotensin: relevance to progression of the disease. J Neurochem., 2009; 109:656-69.

39. Lidstrom AM, Bogdanovic N, Hesse C, Volkman I, Davidsson P, Blennow K. Clusterin (apolipoprotein J) protein levels are increased in hippocampus and in frontal cortex in Alzheimer's disease. Exp Neurol., 1998; 154: 511-21.

40. Morales M, Backman C. Coexistence of serotonin 3 (5-HT3) and CB1 cannabinoid receptors in interneurons of hippo-campus and dentate gyrus. Hippocampus., 2002; 12(6):756-64.

41. Schmitz D, Empson R.M, Heinemann U. Serotonin and 8-OH-DPAT reduce excitatory transmission in rat hippocampal area CA1 via reduction in presumed presynaptic Ca2+ entry. Brain Res., 1995; 701(1-2): 249-54.

42. Auld DS, Mennicken F, Quirion R. Nerve growth factor rapidly induces prolonged acetylcholine release from cultured basal forebrain neurons differentiation between neuromodulatory and neurotrophic influences. JNeurosci., 2001; 21: 3375-82.

43. Baquet ZC, Bickford PC, Jones KR. Brain-derived neurotrophic factor is required for $t$ he establishment of the proper number of dopaminergic neurons in the substantia nigra pars compacta. JNeurosci., 2005; 25: 6251- 9.

44. Butterfield DA, Drake J, Pocernich C, Castegna A. Evidence of oxidative damage in Alzheimer's disease brain: central role for amyloid beta-peptide. Trends in molecular medicine., 2001; 7(12): 548-54.

45. Potkin SG, Anand R, Fleming K, Alva G, Keator D, Carreon D. Brain metabolic and clinical effects of rivastigmine in Alzheimer's disease. Int J Neuropsychopharmacol., 2001; 4(3): 223-30.

46. Forstermann U, Closs EI, Pollock JS, Nakane M, Schwarz P, Gath I, et al. Nitric oxide synthase isozymes, Characterization, purification, molecular cloning, and functions. Hypertension., 1994; 23: 1121-31.

47. Boger RH. The pharmacodynamics of L-arginine. J Nutr., 2007;137(Suppl 2):1650S-55S.

48. Markesbery WR, Carney JM. Oxidative alterations in Alzheimer's Disease. Brain Pathol.,1999; 9: 133-46.

49. Plech A, Klimkiewicz T, Maksym B. Effect of L-arginine on memory in rats. Pol J Pharmacol., 2003; 55(6): 987-92.

50. Bickford PC, Gould T, Briederick L, Chadman K, Polloch A, Young $\mathrm{D}$, et al. Antioxidants-rich diets improve cerebellar physiology and motor learning in aged rats. Brain Res., 2000; 866(1-2): 211-7.

51. Guerrero AL, Dorada-Martinez C, Rodriguez A, Pedroza-Rios K, Borgonio-Perez G, Rivas-Arancibia S. Effects of vitamin E on ozoneinduced memory deficits and lipid peroxidation in rats. Neuroreport., 1999; 10(8): 1689-92.

52. Masliah E, M Mallory, M Alford. Altered expression of synaptic proteins occurs early during progression of Alzheimer's Disease. Neurology., 2001; 56(1):127-9.

53. B. Mravec, L. Horvathova, A. Padova. Brain under Stress and Alzheimer's disease. Cell Mol Neurobiol., 2017; 1-12 doi: 10.1007/s10571-017-0521-1.

54. Cruz-Haces M, Tang J, Acosta G, Fernandez J, Shi R. Pathological correlations between traumatic brain injury and chronic neurodegenerative diseases. Transl Neurodegener., 2017; 6(20):1-10.

55. Craft S, Peskind E, Schwartz MW, Schellenberg GD, Raskind M, and Porte Jr D. Cerebrospinal fluid and plasma insulin levels in Alzheimer's Disease: relationship to severity of dementia and apolipoprotein E genotype. Neurology., 1998; 50: 164-8.

56. Gutteridge JM. Hydroxyl radicals, iron, oxidative stress, and neurodegeneration. Ann. NY Acad Sci., 1994; 738: 201-13.

57. Chomyn A, Attardi G. MtDNA mutations in aging and apoptosis. Biochem Biophys Res Commun., 2003; 304: 519-29.

58. McIntyre CK, Marriott LK, Gold PE. Cooperation between memory systems acetylcholine release in the amygdala correlates positively with performance on a hippocampus-dependent task. Behav Neurosci., 2003; 117(2): 320-6.

59. Schindowski K, Belarbi K, Buée L. Neurotrophic factors in Alzheimer's disease: role of axonal transportGenes. Brain Behav., 2008;7: 4356-69.

60. Takeda A, Loveman E, Clegg A, Kirby J, Picot J, Payne E. A systematic review of the clinical effectiveness of donepezil, rivastigmine and galantamine on cognition, quality of life and adverse events in Alzheimer's Disease. Int J Geriatr Psychiatry., 2006; 21:1728. 


\section{Indo Global Journal of Pharmaceutical Sciences, 2019; 9(1): 5-12}

61. Burns A, O’Brien J, BAP Dementia Consensus group, Auriacombe S, Ballard C, Broich K, et al. Clinical practice with anti-dementia drugs: a consensus statement from British Association for Psychopharmacology. J Psychopharmacol., 2006; 20:732-55.

62. Gauthier S, Emre M, Farlow MR, Bullock R, Grossberg GT, Potkin SG. Strategies for continued successful treatment of Alzheimer's Disease: switching cholinesterase inhibitors. Curr Med Res Opin ,2003; 19:707-14.

63. Tae-Young Hwang, Inn-Sook Ahn, Seonwoo Kim, Doh Kwan Kim. Efficacy of Galantamine on Cognition in Mild-to-Moderate Alzheimer's Dementia after Failure to Respond to Donepezil.Psychiatry Investig., 2016; 13(3):341-8.

64. Elysse M. Knight,Soong Ho Kim,Jessica C. Kottwitz,Asa Hatami,Ricardo Albay, Akinobu Suzuki et al. Effective antiAlzheimer Ab therapy involves depletion of specific $\mathrm{Ab}$ oligomer subtypes. Neurology., 2016; 3:1-10.

65. Katarina Spilovska, Jan Korabecny, Eugenie Nepovimova, Rafael Dolezal, Eva Mezeiova, et al. Multitarget Tacrine Hybrids with Neuroprotective Properties to Confront Alzheimer's Disease. Curr Top Med Chem., 2017; 17(9):1006-26.

66. Nepovimova E1, Uliassi E, Korabecny J, Peña-Altamira LE, Samez S, Pesaresi A, et al. Multitarget drug design strategy: quinone-tacrine hybrids designed to block amyloid- $\beta$ aggregation and to exert anticholinesterase and antioxidant effects. J Med Chem., 2014; 57(20): 8576-89.

67. Catarina Quintanovaa, AméliaSantosa M, ílviaChavesa S, Rangappa S.Keria. Copper (II) complexation of tacrine hybrids with potential anti-neurodegenerative roles. Journal of Inorganic Biochemistry., 2015; 151:58-66.

68. Santos MA1, Chand K1, Chaves S1. Recent progress in repositioning Alzheimer's disease drugs based on a multitarget strategy. Future Med Chem., 2016; 8(17):2113-42.

69. Budni J1, Garcez ML, de Medeiros J, Cassaro E, Bellettini-Santos T, Mina F, Quevedo J. The Anti-Inflammatory Role of Minocycline in Alzheimer's Disease, Curr Alzheimer Res., 2016; 13(12) :1319-29.
70. JustynaGodyń, JakubJończyk, DawidPanek, BarbaraMalawska Therapeutic strategies for Alzheimer's disease in clinical trials, Pharmacological Reports., 2016; 68(1):127-38.

71. Thuy Trang Nguyen, Vo Van Giau, Tuong Kha Vo. Current advances in transdermal delivery of drugs for alzheimer's disease Indian J Pharmacol., 2017; 49(2) :145-154.

72. Leslie K. Ferrarelli. New Connections: Amyloid- $\beta$ in the pathology of Alzheimer's disease. Sci Signal., 2018; 522: aat6003.

73. Cummings J, Lee G, Ritter A, Zhong K. Alzheimer's disease drug development pipeline: 2018. Alzheimer's \& Dementia: Translational Research \& Clinical Interventions., 2018; 4: 195-214.

74. Reeder TM, Harbaugh RE. Direct cerebrospinal fluid infusion of bethanechol chloride in Alzheimer's disease: use of an implantable continuous infusion device. J Neurosurg Nurs., 1985; 17(3): 184-9.

75. Wang R, Yan H, Tang X.C. Progress in studies of huperzine A, a natural cholinesterase inhibitor from Chinese herbal medicine. Acta Pharmacol Sin., 2006; 27: 1-26.

76. Tariska P, Paksy A. Cognitive enhancement effect of piracetam in patients with mild cognitive impairment and dementia. ORV Hetil., 2000; 141: 1189-93.

77. Brooks SP, Hennebry G, McAlpin GP, Norman G, Little HJ Nimodipine prevents the effects of ethanol in tests of memory. Neuropharmacol., 2002; 42(4): 577-85.

78. Wang JM, Singh C, Liu L, Irwin RW, Chen S, Chung EJ, et al. Allopregnanolone reverses neurogenic and cognitive deficits in mouse model of Alzheimer's disease. Proc Natl Acad Sci U S., 2010; 107: 6498-503.

Indo Global Journal of Pharmaceutical Sciences( ISSN 2249 1023; CODEN- IGJPAI; NLM ID: 101610675) indexed and abstracted in CrossRef (DOI Enabling), UGC CARE Journal List, EMBASE(Elsevier), National Library of Medicine (NLM) Catalog, ResearchGate, Publons, CAS (ACS), Index Copernicus, Google Scholar and many more. For further details, visit http://iglobaljournal.com 